\title{
Real-Time Monitoring of Electroconductivity in Plants with Microscale Needle Probes
}

\author{
Eunyong JEON ${ }^{1}$, Sangwoong BAEK ${ }^{2}$ Seungyul $\mathrm{CHOI}^{3}$, Kyoung Sub PARK ${ }^{4}$ \\ and Junghoon $\operatorname{LEE}^{1,2}$ \\ ${ }^{1}$ Graduate School of Convergence Science and Technology, Seoul National University, \\ Gyeonggi-do 16229, South Korea \\ 2 Department of Mechanical and Aerospace Engineering, Seoul National University, \\ Seoul 08826, South Korea \\ ${ }_{3}^{3}$ Optics Laboratory, Material Production Engineering Research Institute, \\ LG Electronics Research Center, Seoul 06763, South Korea \\ ${ }^{4}$ Protected Horticulture Research Institute, National Institute of Horticultural \\ and Herbal Sciences, RDA, Haman 52054, South Korea
}

(Received October 29, 2017; Accepted January 11, 2018)

\begin{abstract}
In plant studies, electrical properties such as the conductivity and resistance are used for measuring the health of a plant or controlling the salinity of a nutrient solution. In recent years, continuous efforts have been undertaken to determine the state of a plant and establish an optimal growth environment by measuring the internal ion concentration of the sap, in plant horticulture. In this paper, we present a needle-shaped measurement sensor for measuring the internal electrical conductivity of a plant. The needle-sensor is targeted at horticultural plants such as cucumber, tomato, and paprika. As horticultural crops have small stem diameters and xylem areas, a minimally invasive measurement approach and measuring electrodes with small form factors are required. The proposed needle sensor has microscale width electrodes and a hundreds-of-microscalewidth needle, enabling local measurement with minimal invasion. The interdigitated electrode was optimized to measure higher range of electrical conductivity $(12.8 \mathrm{mS} / \mathrm{cm})$ of horticultural plants through frequency sweeping analysis. The laboratory-proven sensors were applied to greenhouse-grown cucumbers and the ionic concentrations were monitored during the day and at night, in real time. Results indicate peculiar periodic pattern of electrical conductivity variation with respect to time occurring in the plant xylem.
\end{abstract}

Keywords : controlled horticulture, direct measurement, internal information, minimally invasive

\section{INTRODUCTION}

In plant horticulture, electrical conductivity is used to regulate the salinity and control the condition of the fruit or the plant itself. Salt stress in cucumber cultivation has a negative effect on the overall growth; the higher the value, the greater is the effect (Lechno et al., 1997; Duan et al., 2008; Khan et al., 2013). In the case of tomato, increasing the salinity of the nutrient solution limits water transport, improving the quality of the fruit. However, this watertransport limitation results in lower yield (Mitchell et al., 1991a; Mitchell et al., 1991b; Wu et al., 2004). In order to measure such parameters, existing techniques rely on analyzing the state of a fully-grown fruit or sacrificing the plant itself. As such methods are destructive and inefficient, a nondestructive method that can directly measure the internal information of the plant stem is needed. A direct measurement method can provide real-time information on the growth environment of the plant without adverse effects.

Research on the direct measurement of plant internal information has been preceded by a variety of methods (Tattar and Blanchard, 1976; Dalton et al., 1984) including the measurement of the sap flow using the heat-pulse velocity, heat-field deformation, and thermal dissipation probes (Marshall, 1958; Swanson and Whitfield, 1981; Lu et al., 2004; Nadezhdina et al., 2012). In such techniques, a probe is inserted inside the plant and heat is generated; the velocity is measured by the heat-conduction phenomenon, in accordance with the sap flow. The total amount of water transported from the root of the plant and the transpiration can be predicted using such methods. The Shigometer is a portable system that measures the internal resistance of a plant for predicting its health (Shigo, 1974). A decrease in resistance is observed, when plant decay occurs. However, it is difficult to apply the above systems to plants with thin and weak stems because of the large-sized measurement probes.

To measure the real-time data of such thin and weak plants, we propose a microneedle sensor having a small form factor, with minimal invasion. Microneedle structures are widely used in the field of drug delivery due to their scaling effect and functionality (Prausnitz, 2004). Using

Corresponding author : Junghoon Lee, fax: + 82-2-877-9104, e-mail: jleenano@snu.ac.kr 
conventional semiconductor processes, it is easy to fabricate a small-structured needle with fine patterns for functions such as electrochemical measurements. Previously, we had developed microneedle sensors and successfully measured real-time data with minimal invasion, in horticultural plants. In this paper, the optimization of the electrode design is achieved. Field testing is conducted using a cucumber plant and the real-time electrical conductivity changes are monitored for two d.

\section{MATERIALS AND METHODS}

\section{Microneedle-sensor system}

Experiments were conducted to measure the electrical conductivities of the stems of horticultural crops such as tomatoes and cucumbers. The microneedle sensor is to be inserted into the xylem of the plant stem to contact the fluid. The largest stem diameters of the tomato and cucumber plants used in our experiments were $20 \mathrm{~mm}$. Previous studies have reported 5-20 $\mathrm{mm}$ stem diameters for tomato and cucumber plants cultivated under a controlled growth environment (Kitano et al., 1996; De Swaef and Steppe, 2010; De Swaef et al., 2013; Olle and Williams, 2015). The microneedle sensor was designed to have an insertion length of $5 \mathrm{~mm}$ and each of the three measuring electrodes was placed on the needle in an array format, considering the stem-diameter variations. Semiconductor process technology was used to fabricate a microscale interdigitated electrode array on the sensor needle to achieve the required signal accuracy and minimum invasion to the plant stem (Jeon et al., 2017).

Equation (1) shows the relationship between the electrical conductivity $(\sigma)$, solution resistance $(R)$, and cell constant $(\kappa)$. The cell constant can be expressed by the relationship between the working area of the electrode $(\alpha)$ and the interdistance between the electrodes $(d)$, in equation (2). The electric conductivity can be inversely calculated by obtaining the resistance of the plant sap, for an electrode with a specific geometric value.

$$
\begin{aligned}
\sigma & =\frac{\kappa}{R} \\
\kappa & =\frac{d}{a}
\end{aligned}
$$

Two electrode systems were used to measure the impedance of the plant sap and interdigitated geometry was performed to minimize the current path and increase the accuracy. The cell constant and circuit design model required to select the electrode geometry and measurement frequency were obtained by COMSOL simulation and numerical calculation (Jeon et al., 2017). Further, experiments were performed to evaluate the changes in the frequency characteristics with respect to the electrode length (L), width (W), interdistance of the electrodes (S), and the number of fingers $(\mathrm{N})$.

Figure 1 illustrates the fabricated microneedle chip and the integrated measurement system. The electrical conductivity of the plant sap was measured by converting the impedance between the two electrodes. During the communication between the converter and microcontroller, the current signal is converted to voltage (current-to-voltage amplifier) and finally, to a digital value (digital-to-analog converter). The digitized signal is transmitted to a computer using Bluetooth communication, and the data are stored and visualized through a program.

\section{Cucumber cultivation}

The experiments were performed in a greenhouse at Beopgot-dong, Ilsanseo-gu, Goyang-si, Gyeonggi-do in the Republic of Korea, located at a latitude of $37^{\circ} 39^{\prime} 56.8^{\prime \prime}$ $\mathrm{N}$ and a longitude of $126^{\circ} 42^{\prime} 54.0^{\prime \prime}$ E. Cucumber seeds (wonnongseed, Cucumis sativus L) were sown in 40 holetrays on October 2, 2016. Before the transplantation, the slabs were flushed with nutrient solution at 5.5-5.8 $\mathrm{pH}$, approximately and an electrical conductivity of $1.8 \mathrm{mS} / \mathrm{cm}$. The compositions of the nutrient solution were as follows: Solution $\mathrm{A}=$ calcium nitrate $\left(\mathrm{Ca}\left(\mathrm{NO}_{3}\right)_{2}\right.$, potassium nitrate $\left(\mathrm{KNO}_{3}\right)$, and Iron chelate (Fe-EDTA (ethylene diaminetetraacetate); Solution $\mathrm{B}=$ potassium nitrate $\left(\mathrm{KNO}_{3}\right)$, magne-
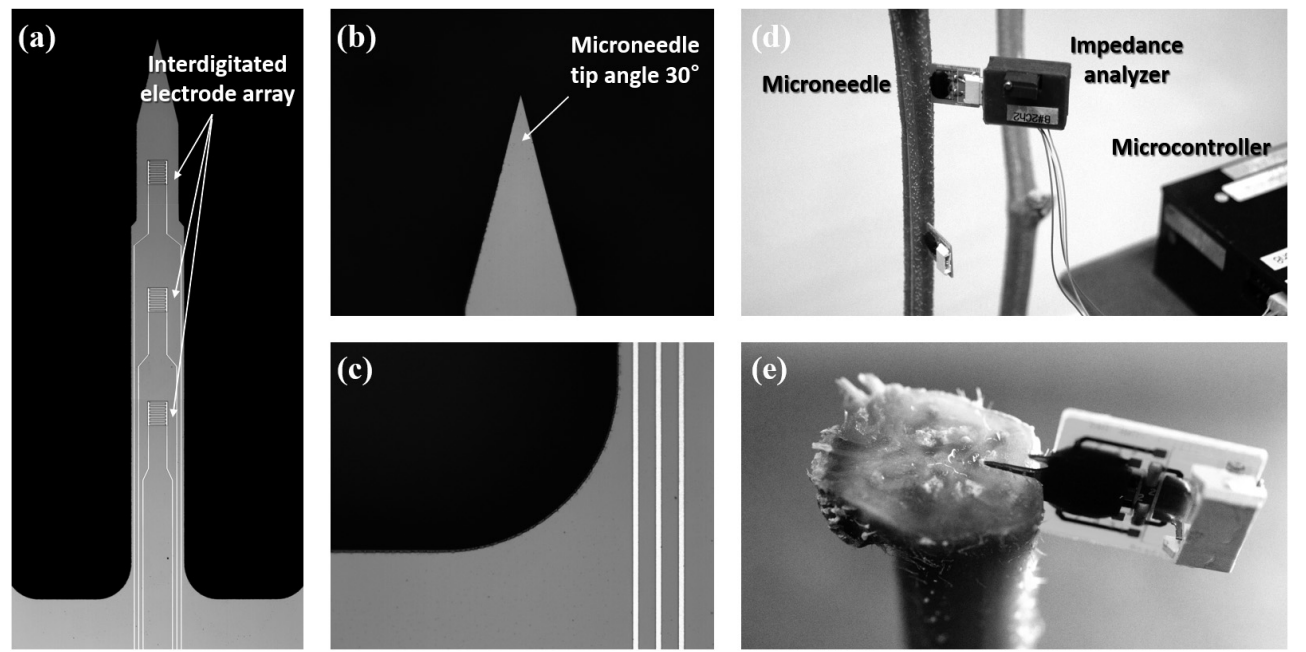

Fig. 1 Microneedle-sensor system: (a) complete picture of the microneedle with an electrode array, (b) $30^{\circ}$ cone-angle needle, (c) robust mechanical design feature, (d) integrated microneedle system, and (e) cucumber-stem cross section with the microneedle sensor. 
sium sulfate $\left(\mathrm{MgSO}_{4}-7 \mathrm{H}_{2} \mathrm{O}\right)$, potassium phosphate monobasic $\left(\mathrm{KH}_{2} \mathrm{PO}_{4}\right)$, and ammonium phosphate monobasic $\left(\mathrm{NH}_{4} \mathrm{H}_{2} \mathrm{PO}_{4}\right)$; micronutrient $=$ boric acid $\left(\mathrm{H}_{3} \mathrm{BO}_{3}\right)$, copper sulfate $\left(\mathrm{CuSO}_{4}\right)$, zinc sulfate $\left(\mathrm{ZnSO}_{4}\right)$, Manganese sulfate $\left(\mathrm{MnSO}_{4}\right)$, and sodium molybdate $\left(\mathrm{Na}_{2} \mathrm{MoO}_{4}\right)$. The cucumber seedlings were transplanted on November 11, 2016 to a commercial slab (Seo Won Co., Cocomix, $15 \times 10 \times 100$ $\mathrm{cm})$. The irrigation of the nutrient solution was adjusted according to the amount of solar radiation, using a drip irrigation system (Priva Maximizer) after transplantation. The electrical conductivity of the nutrient solution was maintained at $2.3 \mathrm{mS} / \mathrm{cm}$ and the $\mathrm{pH}$ was maintained at 5.5-5.8. The humidity of the green house was $70-80 \%$ during the day and $90-95 \%$ at night. The environmental temperature (greenhouse) was controlled in four steps: Sunrise to afternoon $\left(25^{-}-28^{\circ} \mathrm{C}\right)$, afternoon to sunset $\left(23^{-}-25^{\circ} \mathrm{C}\right), 3 \mathrm{~h}$ after sunset $\left(15^{-16} 6^{\circ} \mathrm{C}\right)$, and until sunrise $\left(13^{\circ} \mathrm{C}\right)$. The real-time environmental conditions such as the solar radiation $\left(\mathrm{W} / \mathrm{m}^{2}\right)$, temperature $\left({ }^{\circ} \mathrm{C}\right)$, relative humidity $(\mathrm{RH} \%)$, and the carbon dioxide dose were monitored using built-in sensors (Priva Maximizer) in the greenhouse.

\section{RESULTS AND DISCUSSION}

Electrode-geometry dependent microneedle-system frequency characteristics

The relatively small stem diameters of horticultural crops necessitate micro-sized electrodes for accessing the small xylem sections. Although the sensitivity and applicability of the electrode were enhanced by its miniaturization, the electrical-conductivity of the usable solution was limited, in accordance with the reduction of the working electrode size. Previous studies have shown that the electrical conductivity of the nutrient solution used for the soilless cultivation of vegetables was $0.8-3.7 \mathrm{mS} / \mathrm{cm}$ (Savvas and Adamidis, 1999). In the case of tomatoes, it does not exceed $10 \mathrm{mS} / \mathrm{cm}$. (Dorais et al., 2001). As the electrode design was optimized for application to a horticulture-cultivation environment, the measurement range was set to 12.8
$\mathrm{mS} / \mathrm{cm}$. Figure 2 (a) shows the impedance vs frequencysweeping results of the interdigitated electrode. The measurement system, using an LCR meter (Agilent E4980A), was operated from $0-2 \mathrm{MHz}$, at $0.5 \mathrm{~V}$, with geometric parameters of $\mathrm{S}=10, \mathrm{~W}=5, \mathrm{~L}=138, \mathrm{~N}=14 \mu \mathrm{m}$. The resistive dominant regions (Rs) were distinguished, according to the conductivity of the solution. In addition, the high (h) and low (1) cut-off frequencies can be defined.

The cell constant of the interdigitated electrode was calculated, as mentioned earlier. We designed the electrodes with two different configurations: $(\mathrm{W}=3, \mathrm{~S}=2$, $\mathrm{L}=153) \mu \mathrm{m}, \mathrm{N}=20$ for the first-configuration and $(\mathrm{W}=5$, $\mathrm{S}=10, \mathrm{~L}=138) \mu \mathrm{m}, \mathrm{N}=14$ for the second. The cell constant of each electrode was calculated to be $5.763 / \mathrm{cm}$ and $12.967 / \mathrm{cm}$, respectively (capacitance method) (Jeon et al., 2017). Figure 2 (b) summarizes the shift in the high and low cut-off frequencies due to electrode-geometry modification. An upward shift in the resistive-dominant area, and a shift of the high and low cut-off frequencies to a lower frequency range are observed. The impedance spectrum, depending upon the concentration, is the largest in the resistive-dominant region. If this region appears in a narrow or too-high frequency range, the non-linear phenomenon of the calibration curve in small measuring instruments is maximized with a low, usable frequency range. From the frequency-sweeping results, it is confirmed that the Rs window is shifted to a low-frequency band; hence, a higher saline-solution concentration can be measured. The nonlinearity of the measured value was also minimized.

\section{Field-test results}

Figure 3 displays the data measured for two days, after the installation of the sensor on the cucumber stem. Two microneedle sensors were installed on different cucumber stems $(\mathrm{N}=2)$, near the roots and data were collected. However, as mentioned in previous research reports, the temperature change inside the plant is negligible compared to the outside temperature change. In addition, the temperature effect of the microneedle sensor was $0.614 \%$ per degree, which is a minor contribution to the (a)

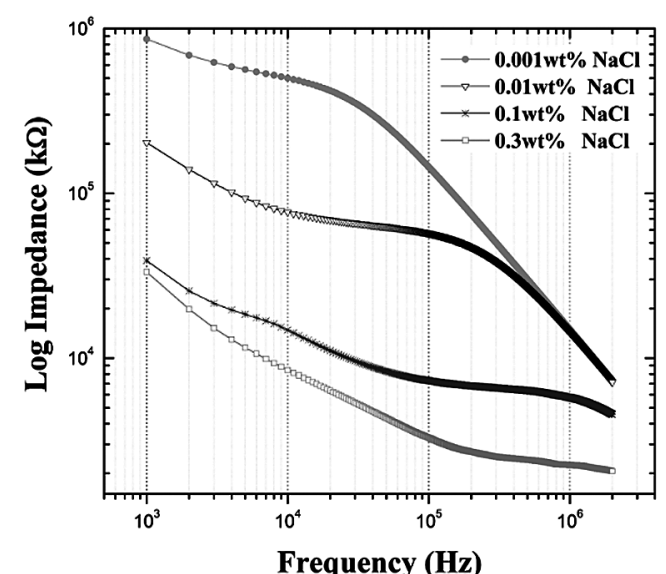

(b)

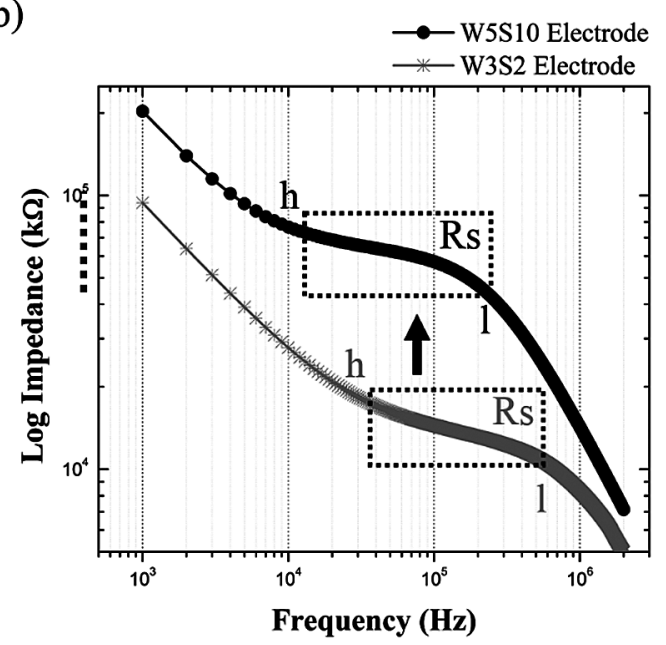

Fig. 2 Frequency-dependent characteristics: (a) frequency-sweeping results, according to the saline-solution concentration, (b) electrodegeometry dependent frequency characteristic of the interdigitated electrode $(\mathrm{W}=$ width of the finger electrode, $\mathrm{S}=$ interdistance between the finger electrodes, $\mathrm{L}=$ finger-electrode length, $\mathrm{N}=$ number of finger electrodes). 
Sensor $1(\mathrm{mS} / \mathrm{cm})$

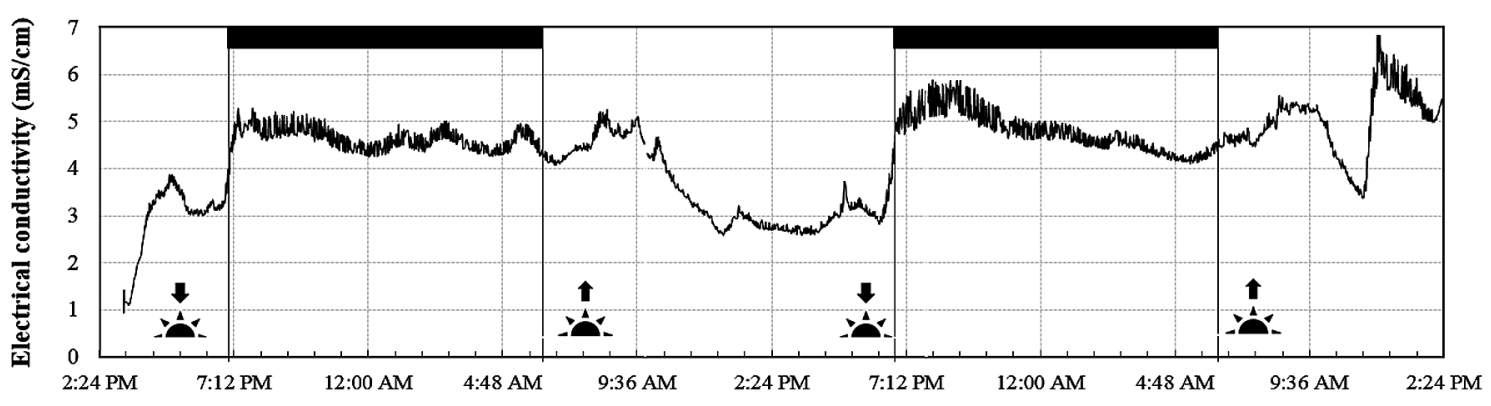

Sensor 1_Temperature

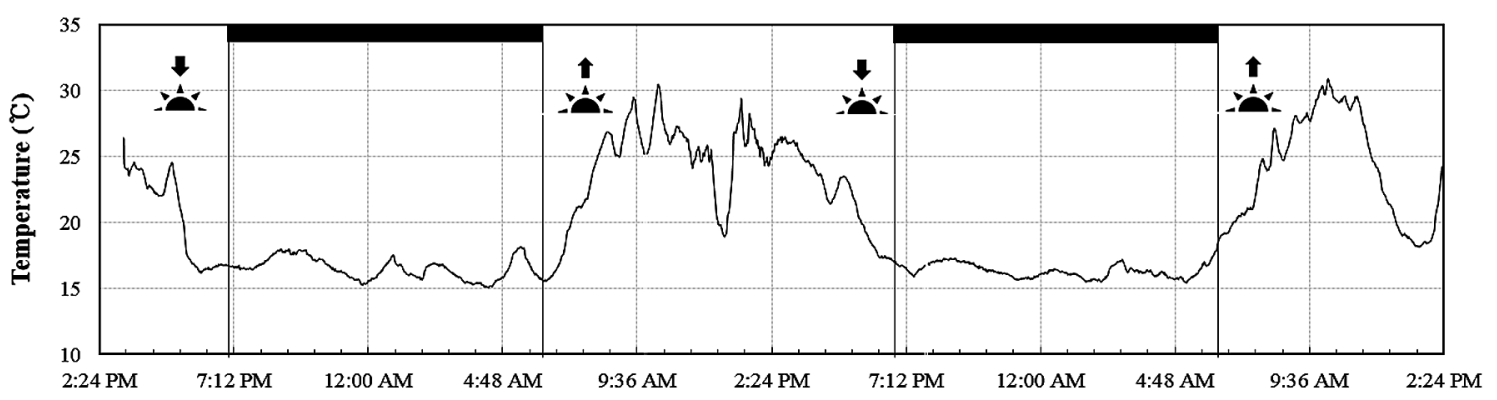

Sensor $2(\mathrm{mS} / \mathrm{cm})$

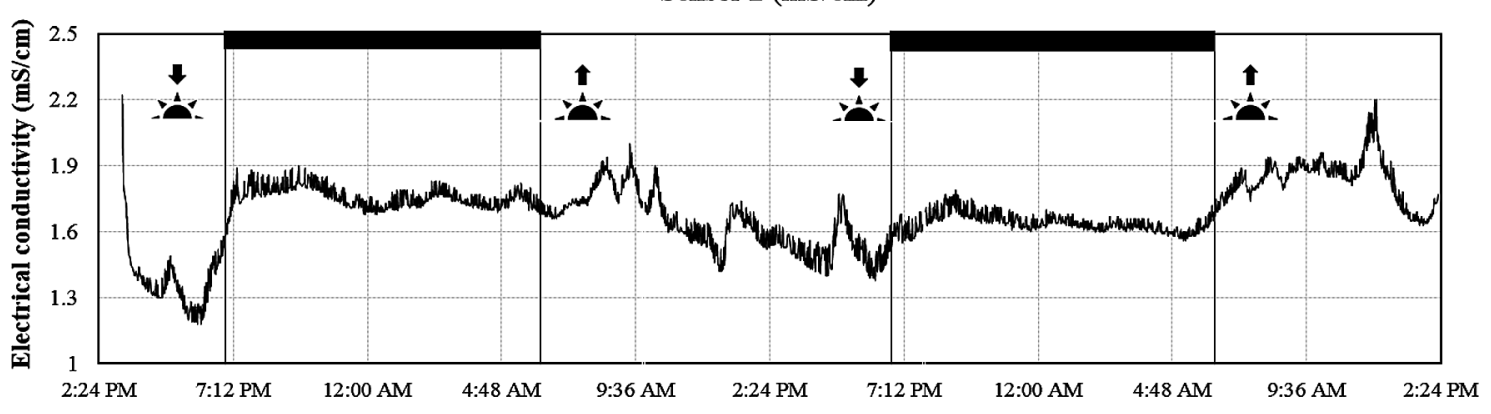

Sensor 2_Temperature

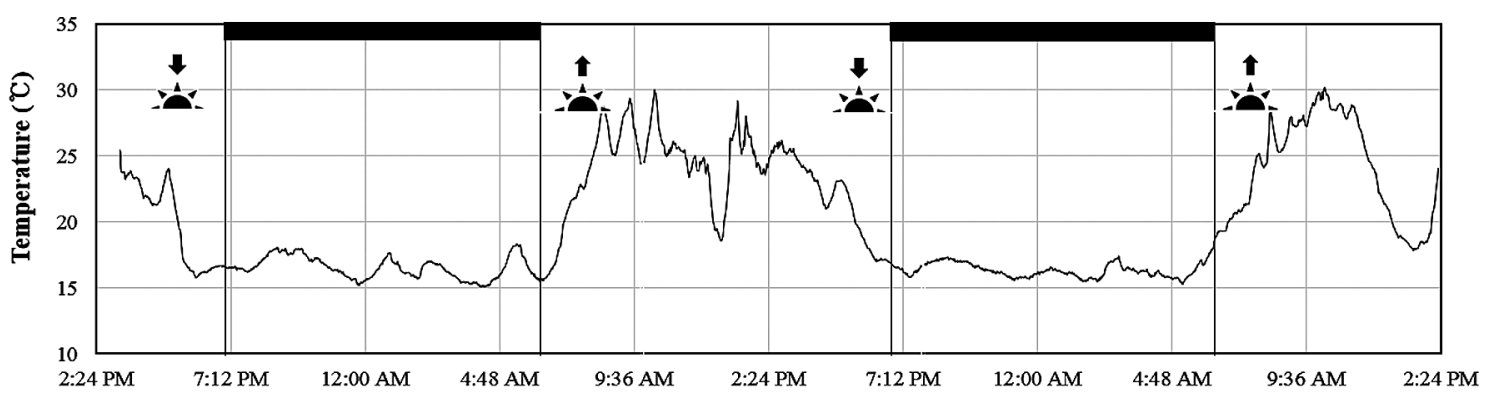

Fig. 3 Real-time monitored electrical conductivity data of cucumbers. Sunrise and sunset are indicated pictorially in the figure. The day and night periods are indicated by black and white color on top of the graph.

overall measurement (Jeon et al., 2017).

Three findings can be identified from the real-time electrical conductivity monitoring of cucumber plants. First, the level of the sap electrical conductivity measured for cucumber. The internal components of the plant sap approximate the components of the displaced soil solution. In the past, this has been confirmed using the bleeding method (Lowry and Tabor, 1931). The electrical conductivity of cucumber, in this experiment, was maintained at 2.3 $\mathrm{mS} / \mathrm{cm}$. Considering the value of the maintained electrical conductivity, the measured electrical conductivity value was found to be reasonable. Second, daily cycle changes were observed. The electrical conductivity at night is relatively higher than at daytime. Plants have different day and night ion concentrations. The concentrations of the major plant ions $(\mathrm{K}, \mathrm{Ca}, \mathrm{Mg}, \mathrm{P}, \mathrm{Na}$, etc.) tend to decrease at daytime, increasing at night (Peuke et al., 2001). The electrical conductivity results of the sensor indicate this cyclic nature. Third, the xylem can be specifically accessed through the measured signal pattern. Both sensor data ex- 
hibit different electrical-conductivity levels and behavior. In the case of sensor 1 , the periodicity and the change can be observed clearly. However, sensor 2 exhibited a reasonable electrical conductivity value but no apparent ion change was observed. By analyzing the measured signal pattern using the ion-change characteristics of the xylem, it is possible to verify the zone for needle insertion. The overall sensor measurement signal exhibited high noise in the high-electrical-conductivity region (over $4 \mathrm{mS} / \mathrm{cm}$ ), in particular. This is caused by the nonlinear characteristics of the calibration curve.

\section{CONCLUSION}

We fabricated a minimally invasive microscale needle sensor, using semiconductor process technology. The insertable microneedle was utilized to measure real-time changes in the electrical conductivity of cucumber stems. Current techniques enable us to measure the ionic concentration of plant stems using chemical analysis. However, such techniques are destructive and the plant has to be sacrificed. The fabricated microneedle sensor along with the developed electrical measurement system successfully measured the periodic characteristics of the ions within the plant by real-time simultaneous monitoring. In hydroponic cultivation, analysis of the nutrient solution discharged from the slab, and the evaluation of the quantity and quality of the plant fruit is needed to optimize the plant cultivation environment. The currently available techniques are complex and less effective in terms of managing the amount of fertilizer-waste, in a hydroponic system. Internal measurements can determine the nutrient-solution level accepted through the roots of the plant and it can be used to control the fertilizer effectively. We believe that our technology can contribute significantly in understanding plant physiology and result in better quality crops with higher yield, in future.

\section{ACKNOWLEDGMENT}

This research was supported by the Rural Development Administration (PJ012100022016), Republic of Korea, and by the Bio-Mimetic Robot Research Center funded by the Defense Acquisition Program Administration and by the Agency for Defense Development (UD130070ID). The fabrication was done at the Inter-University Semiconductor Research Center (ISRC) in Seoul National University.

\section{REFERENCES}

Dalton, F. N., Herkelrath, W. N., Rawlins, D. S., Rhoades, J. D. 1984. Time-domain reflectometry: simultaneous measurement of soil water content and electrical conductivity with a single probe. Science 224: 989-990.

De Swaef, T., Driever, S. M., Van Meulebroek, L., Vanhaecke, L., Marcelis, L. F. M., Steppe, K. 2013. Understanding the effect of carbon status on stem diameter variations. Ann. Bot. 111: 31-46.

De Swaef, T., Steppe, K. 2010. Linking stem diameter varia- tions to sap flow, turgor and water potential in tomato. Funct. Plant Biol. 37: 429-438

Dorais, M., Papadopoulos, A., Gosselin, A. 2001. Influence of electric conductivity management on greenhouse tomato yield and fruit quality. Agronomie 21: 367-383.

Duan, J. J., Guo, S. R., Kang, Y. Y., Li, J., Liu, X. E. 2008. Effects of salt stress on cucumber seedlings root growth and polyamine metabolism. (in Chinese with abstract in English) Ying Yong Sheng Tai Xue Bao 19: 57-64.

Jeon, E., Choi, S., Yeo, K. H., Park, K. S., Rathod, M. L., Lee, J. 2017. Development of electrical conductivity measurement technology for key plant physiological information using microneedle sensor. J. Micromech. Microeng. 27: 085009.

Khan, M. M., Al-Mas'oudi, R. S. M., Al-Said, F., Khan, I. 2013. Salinity effects on growth, electrolyte leakage, chlorophyll content and lipid peroxidation in cucumber (Cucumis sativus L.). Int. Proc. Chem. Biol. Environ. Eng. 55: 28-32.

Kitano, M., Hamakoga, M., Yokomakura, F., Eguchi, H. 1996. Interactive dynamics of fruit and stem growth in tomato plants as affected by root water condition. I. Expansion and contraction of fruit and stem. Biotronics 25: 67-75.

Lechno, S., Zamski, E., Tel-Or, E. $1997 . \quad$ Salt stress-induced responses in cucumber plants. J. Plant Physiol. 150: 206-211.

Lowry, M. W., Tabor, P. 1931. Sap for analysis by bleeding corn plants. Science 73: 453.

Lu, P., Urban, L., Zhao, P. 2004. Granier's thermal dissipation probe (TDP) method for measuring sap flow in trees: theory and practice. Acta Bot. 46: 631-646.

Marshall, D. C. 1958. Measurement of sap flow in conifers by heat transport. Plant Physiol. 33: 385-396.

Mitchell, J. P., Shennan, C., Grattan, S. R. 1991a. Developmental changes in tomato fruit composition in response to water deficit and salinity. Physiol. Plant. 83: 177-185.

Mitchell, J. P., Shennan, C., Grattan, S. R., May, D. M. 1991 b. Tomato fruit yields and quality under water deficit and salinity. J. Am. Soc. Hortic. Sci. 116: 215-221.

Nadezhdina, N., Vandegehuchte, M. W., Steppe, K. 2012. Sap flux density measurements based on the heat field deformation method. Trees 26: 1439-1448.

Olle, M., Williams, I. 2015. The influence of effective microorganisms on the growth and nitrate content of vegetable transplants. JOAAT 2: 25-28.

Peuke, A. D., Rokitta, M., Zimmermann, U., Schreiber, L., Haase, A. 2001. Simultaneous measurement of water flow velocity and solute transport in xylem and phloem of adult plants of Ricinus communis over a daily time course by nuclear magnetic resonance spectrometry. Plant Cell Environ. 24: 491-503.

Prausnitz, M. R. 2004. Microneedles for transdermal drug delivery. Adv. Drug Delivery Rev. 56: 581-587.

Savvas, D., Adamidis, K. 1999. Automated management of nutrient solutions based on target electrical conductivity, $\mathrm{pH}$, and nutrient concentration ratios. J. Plant Nutr. 22: 1415-1432.

Shigo, A. L. 1974. Detection of discoloration and decay in living trees and utility poles. Forest Service, U.S. Dept. of Agriculture, Northeastern Forest Experiment Station.

Swanson, R. H., Whitfield, D. W. A. 1981. A numerical analysis of heat pulse velocity theory. J. Exp. Bot. 32: 221-239.

Tattar, T. A., Blanchard, R. O. 1976. Electrophysiological research in plant pathology. Annu. Rev. Phytopathol. 14: 309325.

Wu, M., Buck, J. S., Kubota, C. 2004. Effects of nutrient solution EC, plant microclimate and cultivars on fruit quality and yield of hydroponic tomatoes (Lycopersicon esculentum). Acta Hortic. 659: 541-547. 
